\title{
Building Information Modeling for Cultural Heritage: The Management of Generative Process for Complex Historical Buildings
}

\author{
F. Banfi ${ }^{1,2\left({ }^{\star}\right)}$, L. Chow ${ }^{1}$, M. Reina Ortiz ${ }^{1}$, C. Ouimet ${ }^{3}$, and S. Fai ${ }^{1}$ \\ ${ }^{1}$ Carleton Immersive Media Studio (CIMS), Carleton University, Ottawa, Canada \\ \{lchow, sfai\}@eims. carleton.ca, \\ MiquelReinaOrtiz@cmail.carleton.ca \\ 2 ABC Department, Politecnico di Milano, Piazza Leonardo da Vinci 32, Milan, Italy \\ fabrizio.banfi@polimi.it \\ ${ }^{3}$ Heritage Conservation Services, PSPC, Quebec, Canada \\ Christian.Ouimet@tpsgc-pwgsc.gc.ca
}

\begin{abstract}
Building Information Modeling (BIM) enhances the sharing of information during the traditional process for new construction, but most of the time, it requires high levels of knowledge management for the historical digital model (H-BIM). The innovation in the Digital Cultural Heritage (DCH) domain is supported by the development of Information and Communications Technologies (ICT) and modern tools that are able to transmit morphological characteristics of the buildings in all their uniqueness. The latest research in the field of H-BIM shows a significant emergence of innovative methods and management initiatives for the generation of complex historical elements, leading to the confrontation of the paradigm of regularity (simple geometric shapes) with the new paradigm of complexity (historical building elements). This paper proves the benefits of the BIM for project management of the Centre Block of the Canadian Parliament in Ottawa, Ontario Canada, and shows the results obtained by the introduction of Advanced Modeling Techniques (AMT) during the generative process, reducing time and cost for the creation of the complex architectural and structural elements. The uniqueness of the forms of historical buildings is a real value to be transmitted throughout the building's lifecycle with high Levels of Detail (LOD). Proper management of geometric primitives and Non-Uniform Rational Basis Spline (NURBS) models have guaranteed the conversion of spatial data (point clouds) from laser scanning and photogrammetry (geometric survey) into parametric applications. This paper explores the generative process of one of the most complex spaces within The Centre Block building of Parliament Hill-Confederation Hall.
\end{abstract}

Keywords: Historic building information modelling (HBIM)

Advanced modeling techniques (AMT)

Non-Uniform rational basis spline (NURBS) · Level of detail (LOD) · Accuracy 


\section{Introduction}

Building Information Modeling (BIM) is an innovative modelling methodology able to improve the management of new construction projects and assemble large amounts of information during the lifecycle of the building. In recent years, BIM has also become viable in the field of built heritage, favouring the restoration and management processes of historic buildings in a digital environment $[2,8]$. Although BIM is typically best suited for new construction, the development of a historical model (HBIM) for historic buildings and complex existing structures can also benefit from the uses of this emerging technology.

The intricate reality of the built heritage and the growing need to represent the actual geometry using free-form modeling collide with the new paradigms of complexity and accuracy, opening a novel operative perspective for the management of historic building with the different type of technologies and BIM-based analysis [3]. Thanks to laser scanning technology and photogrammetry for a BIM specialist is easier to create the asbuilt BIM (AB-BIM). This study presents an Advanced Modeling Technique (AMT) for historic heritage buildings, which integrate the free-form modeling and NURBS algorithms with additional parameterization to orientate the BIM to the correct level of detail (LOD) and accuracy (LOA).

The Carleton Immersive Media Studio (CIMS), a Carleton University Research Centre dedicated to using digital technologies for architectural rehabilitation and heritage conservation, developed a building information model for Centre Block - one of Canada's most significant heritage assets. Confederation Hall — a celebrated interior heritage space of Centre Block — has been an appropriate research subject for studying the improvement of Advanced Modeling Techniques (AMT) and the creation of specific databases composed of historical structural detailed 3D objects.

\subsection{Parliament Hill: The History of Centre Block}

The Parliament Hill National Historic Site comprises the Library of the Parliament, Centre Block, West Block, and East Block. These four buildings are considered exemplary models of the gothic revival style. Centre Block, the central building on Parliament Hill, is the home to Canada's parliamentary democracy - housing both the House of Commons and the Senate.

In 1916, the original Centre Block building was destroyed by a fire, and the design for a new Centre Block was started promptly by architects Jean Omer Marchand and John A. Pearson. The new design was a six-story building with the ninety-two meter Peace Tower as its centrepiece. The building was constructed as a hybrid structure of structural steel framing and load-bearing masonry, a new technology at the time that improved fire protection and allowed for taller and lighter buildings.

In 1986, Centre Block (see Fig. 1) was designated as a Classified Federal Heritage Building primarily for its significance as a national landmark and its architectural value. 


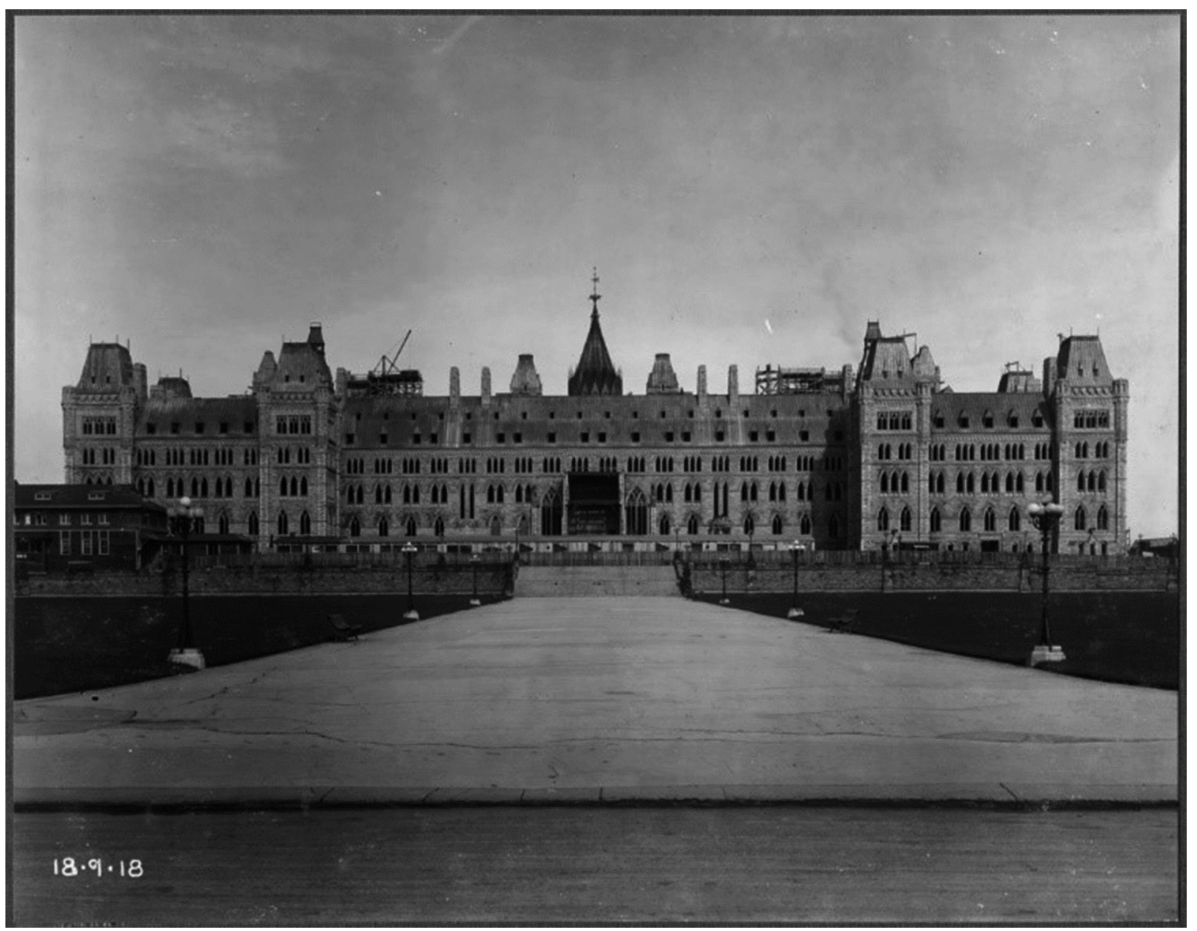

Fig. 1. Historical Picture of the Centre Block under construction. Date: 1918-09-18 Source: Library and Archives Canada, Image\#e010865984

\subsection{The Centre Block Rehabilitation Project}

The century-old Centre Block building (see Fig. 2) will undergo a major rehabilitation program commencing in 2018. In preparation for the Centre Block Rehabilitation Project program of work, CIMS developed a Building Information Model (BIM) in partnership with Heritage Conservation Services (HCS) and the Parliamentary Precinct Directorate (PPD) of Public Services and Procurement (PSPC). The upcoming rehabilitation project will be PSPC's largest and most complex rehabilitation project to date (Government of Canada, 2017).

The ten-year-long rehabilitation project includes updating mechanical, electrical and plumbing systems, security, and communications technology, as well as restoring masonry, seismic upgrades, stabilising existing windows and replacing roofing [9]. 

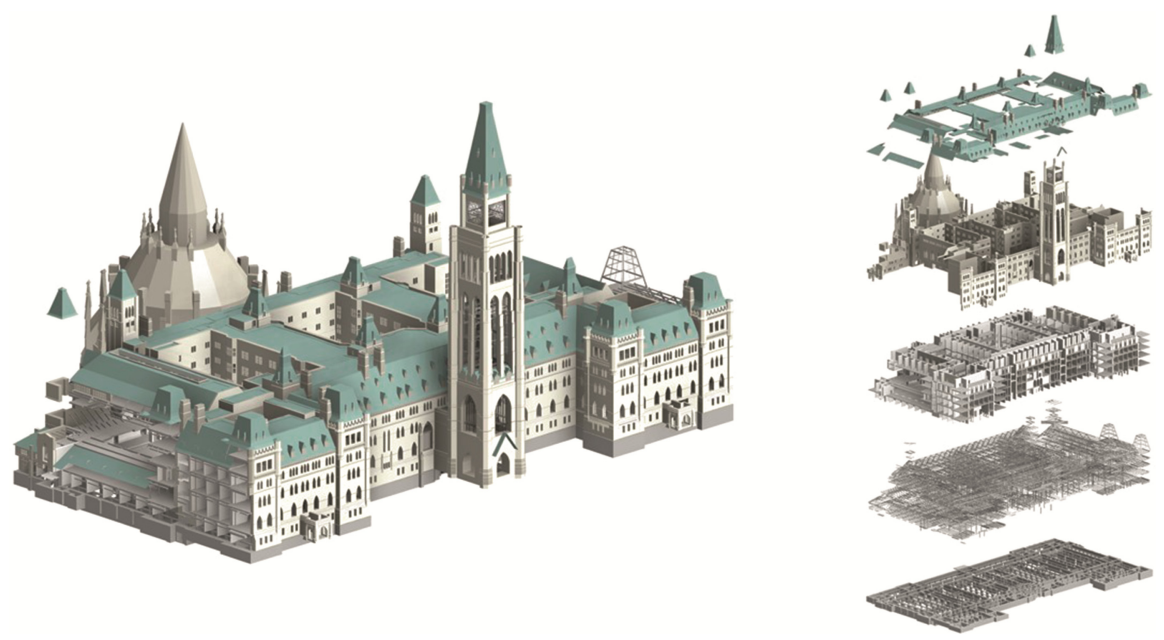

Fig. 2. Building Information Model of Centre Block. Parliament Hill, Ottawa, Canada. Source: Carleton Immersive Media Studio 2017

\subsection{The Centre Block: A BIM-Based Solution for Built Heritage}

Included within the project mandate for the Centre Block Rehabilitation Project was the creation of existing conditions BIM. The intention of creating a BIM was to facilitate an integrated project delivery (IPD) method for the Centre Block Program of Work. According to the American Institute of Architects (AIA), IPD is defined as "a project delivery approach that integrates people, systems, business structures, and practices into a process that collaboratively harnesses the talents and insights of all project participants to optimise project results" (AIA National, 2007) [1].

Although not required for IPD, the use of BIM can help facilitate the early collaboration of all project parties resulting in increased efficiency and the reduction of errors (Kent, Becerik-Gerber, 2010). In addition to capturing the existing conditions of the building, the model was developed in anticipation of specific model uses that follow industry best practice including, but not limited to, the generation of drawings, site analysis, design coordination, and design authoring.

In order to meet the goals mentioned above, the level of detail (LOD) and level of information (LOI) required for each building element category required specification. The level of detail - relating to the graphical information within the model - ranged from LOD 300-500. The LOI - related to the non-graphical information - for each building element varied based upon the availability of information for in situ building elements $[6,7]$. The Centre Block BIM required the synthesis of heterogeneous data sets, including geo-referenced point cloud data, photogrammetry, archival drawings, historical structural steel catalogues, and historical photographs. The geo-referenced point cloud data was the primary source of data, with the remaining sources of data acting as secondary sources for when point cloud data was not available. 


\section{The Research Case Study}

\subsection{The New Paradigm of Complexity for HBIM: The Confederation Hall}

The Confederation Hall is the case study developed in this paper. It is the central space just beyond the main entrance that symmetrically divides the Centre Block.

The octagonal chamber is organised in two different levels: the ground floor and the upper gallery. Limestone clustered columns divide the perimeter; themselves subdivided by dark green syenite pillars. A vaulted ambulatory supports the upper gallery. The arcaded arches are supported on one side by the hall's fan-vaulted ceiling and on the other on a single column in the centre of the room-a stone carved element with an image of Neptune (see Fig. 3).

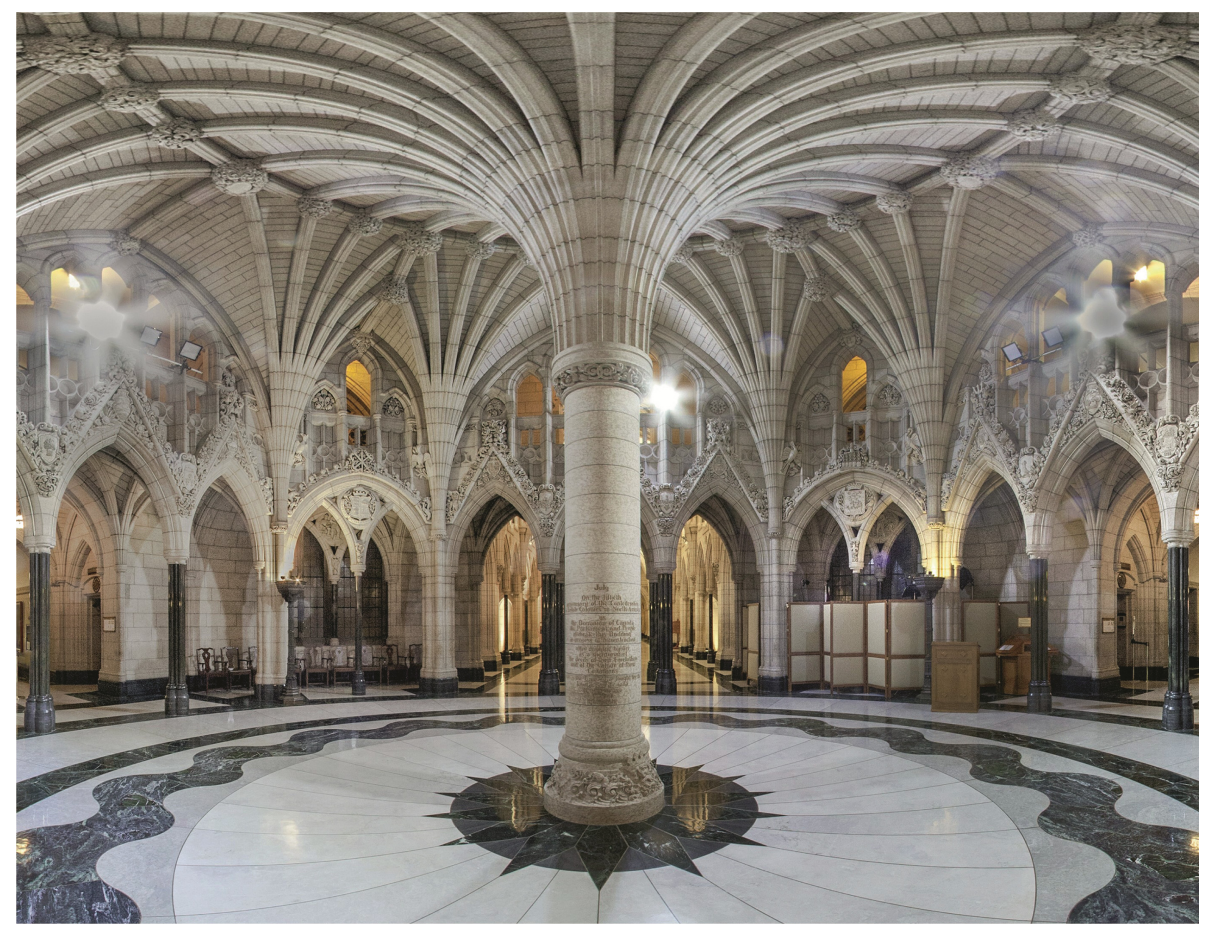

Fig. 3. The Confederation Hall of the Centre Block. Source: Carleton Immersive Media Studio 2017 (Color figure online)

The Confederation Hall was the last part of the Centre Block's interior to be completed. This structure is adorned with stone carvings including the coats of arms of Canada and the provinces and prominent symbols from Canadian life. This space was considered significant as a case study due to its importance within the whole construction and history of the building as its high level of detail in craftsmanship. 


\subsection{Problem Statement: Challenge in BIM Generation}

BIM applications are characterised by internal databases made up of object families. Each family includes different types of 3D objects. Each 3D object matches architectural and structural elements in reality such as the wall, ceiling, ceiling, pillar, roof, etc. The absence of 3D objects corresponding to complex historical elements in BIM database requires the creation of three-dimensional objects through a set of modeling commands. The latter is limited to a number of commands, including but not limited to, extrusion, sweep and swept blend. These commands allow users to create any shape and object, but the generative process requires long production times.

The free-form modeling differs from parametric modeling because it allows creation any form thanks to mathematical logic based on NURBS algorithms.

The main challenge for the implementation of the digital model of the Confederation Hall has been the integration of primary data sources (point clouds), secondary data sources (archival and CAD drawings, historical documents) and NURBS elements into BIM application with high levels of accuracy and detail.

Specifically, the following study emphasises the need for NURBS algorithms into BIM application. The novel generative method of the Confederation Hall has reached an automatic interpolation of the points that make up each 3D scan, transferring complex NURBS 3D elements from modeling software such as Rhino, Maya, etc. into BIM applications such as Revit and Archicad and structural analysis applications such as Midas, Abaqus, Teckla, etc. [4, 5].

\subsection{Research Objectives}

The development of a parametric model of the Confederation Hall for structural analysis has required the following research objectives:

- The lack of existing object libraries required the development of specific 3D objects by Advanced Modeling Tools (AMT) based on different type of data such as historical documentation and geo-referenced survey data.

- Integration of Non-Uniform Rational Basis-Splines (NURBS) into parametric applications (Autodesk Revit) in order to reduce the time and cost of the generative process of Historic Building Information Modeling (H-BIM)

- Improve the Level of Detail (LOD) and the Level of Accuracy (LOA) of each structural 3D object of the Confederation Hall with a deviating value of $1 / 2 \mathrm{~mm}$ between Point Cloud and 3D elements.

- To achieve an Automatic Verification System (AVS) of the Deviation Value between accurate point - clouds and 3D Objects to favour a precise description of how the model has been generated. 


\section{The Generative Process for Complex Structures}

\subsection{The Real Value of HBIM}

In recent years, different studies have proposed innovative solutions to improve the quality of digital models for historic buildings [10]. The tangible and intangible values of the built heritage represent a cultural value for our modern society. The HBIM has allowed a holistic management of different types of information and has guided high levels of knowledge through the use of databases, table and schedules [5].

This integrated system has allowed the creation of a model that considers the building's richness of every single element and to share information through a Revit-shared project over time. Laser scanning and photogrammetry (primary data source) have allowed the definition of the outer part of each architectural and structural element, on the other hand, historical drawings, reports, etc. (secondary data source) have allowed the identification of the historical constructive techniques of the main vaulted system, lancet arches and stone decorations. As the point clouds reflect the geometric complexity of the historic construction, the digital model has reflected the geometric irregularity without an excessive standardisation of structural elements. This has been a fundamental aspect of this study oriented to improve structural simulation based on irregular and complex elements. The uniqueness and authenticity of historic buildings have preserved towards a more exhaustive simulation with a limited extra-cost in terms of processing time.

\subsection{Primary and Secondary Data Sources: Laser Scanning, Photogrammetry and Historical/2D CAD Drawings}

The integration and use of existing heritage building's documentation for 3D digital reconstruction is an innovative challenge that typically involves a management of heterogeneous datasets such as 3D survey data, CAD and historical drawings, tables and schedules, 3D non-contact imaging data and photographs. BIM can incorporate semantic data pertaining to physical characteristics such as structural materials, stratigraphic data, the behaviour of the material, etc. On the other side, HBIM needs to be given the resources to enable it to accomplish its tasks as a matter of urgency. BIM-based analysis requires high LOD and LOI in order to improve the test results and advanced simulation. The primary data source was georeferenced point cloud data from terrestrial laser scanning and photogrammetry (see Fig. 4). The data was captured by CIMS in partnership with Heritage Conservation Services (HCS), PSPC, using a Leica C10 and P40 (exterior and large interior spaces) and a Faro Focus (small to mid-sized interior spaces). Significant heritage interiors including the Senate, Senate Foyer, House of Commons, House of Commons Foyer, Rotunda, Hall of Honour and the exterior of the Peace Tower were also captured by HCS using photogrammetry. Secondary sources such as archival drawings, photographs, historical steel catalogues, and technical reports were referenced in cases where point cloud data was not available (see Fig. 5). 


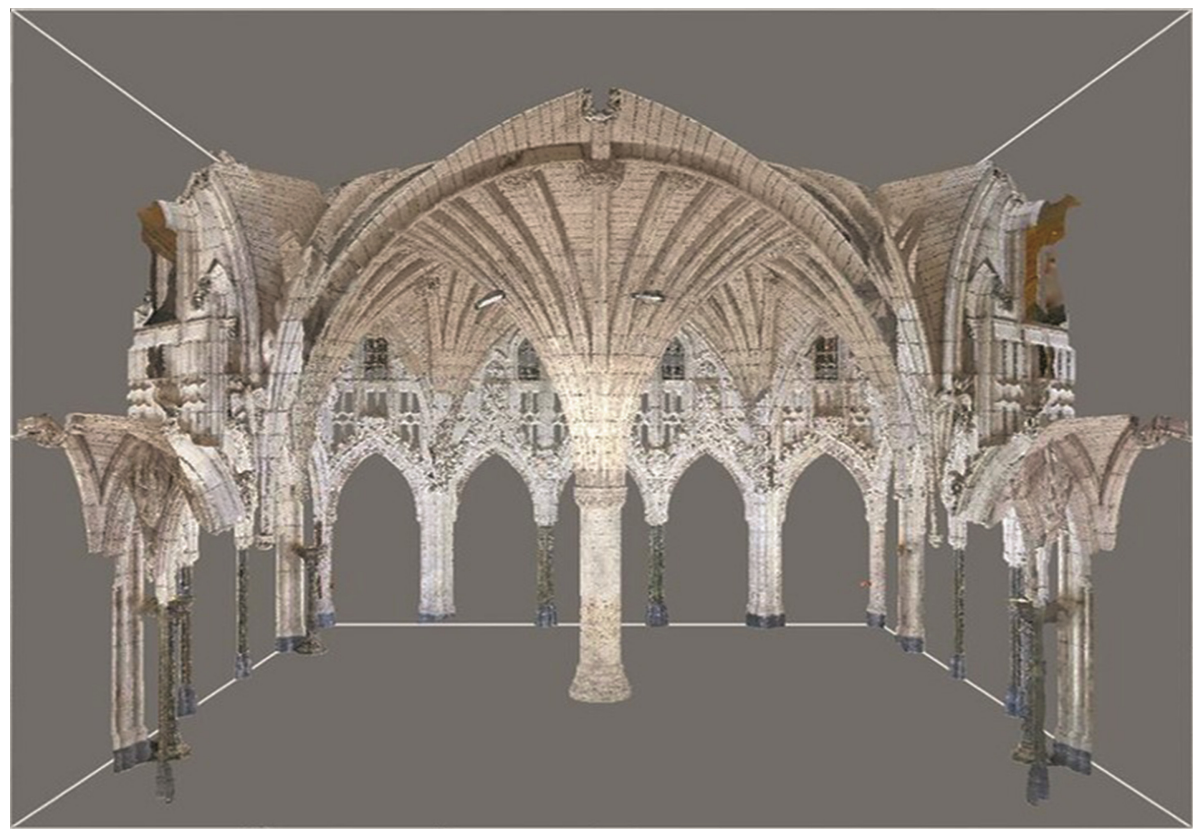

Fig. 4. Dense Point cloud of Rotunda. Centre Block. Photogrammetry from Heritage Conservation Services, PSPC 2017

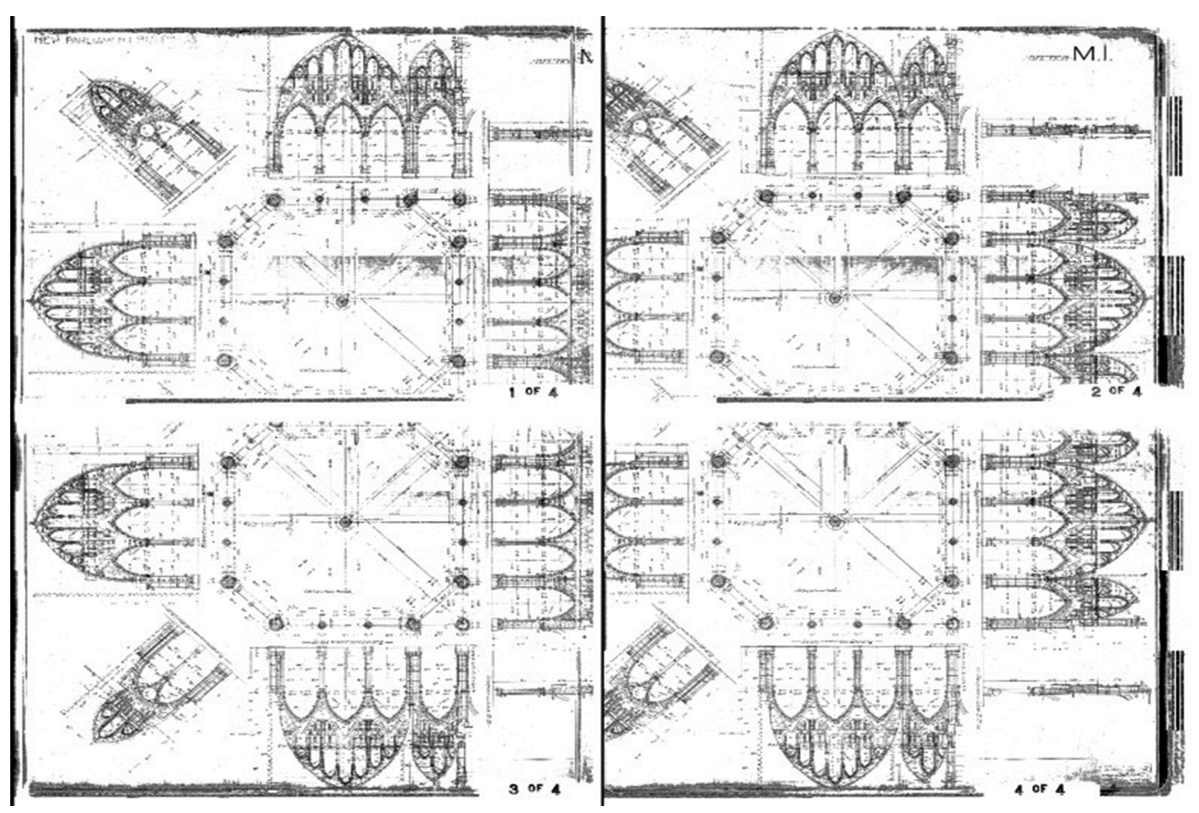

Fig. 5. Historical drawings of Rotunda. Centre Block. Main entrance hall floor plan. Pearson \& Marchand Architects. Date 1920-05-20. Source: National Archives 1999, Reference\#3890. 


\subsection{BIM Generation for Complex Structural Elements: Advanced Modeling Techniques and NURBS Algorithms}

The accuracy of forms detected by using laser scanning, photogrammetry, drones and total station (3D data capture) clashes with the standardisation of 3D objects in the BIM databases. Each single structural element has its characteristics both in morphological and typological terms. The latter has been enhanced thanks to the proper use of NURBS interpolation algorithm which has allowed the automatic and semi-automatic extraction of geometric primitives (splines, polylines, etc., slices) directly from point clouds [9].

Non-Uniform Rational B-Splines (NURBS) algorithms have allowed the generation of complex elements and link difference structural application such as Midas FEA, Abaqus, SAP 2000 etc. NURBS interpolation algorithms for spline and complex surfaces has been employed to construct an exact geometric model.

As shown in Fig. 6, the proposed method is characterised by four steps:

1. The determination of the point cloud portion exactly matches the element to be generated. Thanks to the integrated use of the latest generation software such as Context Capture, Pointools, Scene, and Recap, it has been possible to orient, clean and decimate the point clouds with the aim of obtaining an appropriate base ready to be used for the model generation.

2. Many CAD programs use the term spline to describe an interpolated curve. Later it is obtained thanks to the application of the NURBS interpolation. Free-form modeling software like Mc Nell Rhinoceros has allowed the automatic extraction of geometric primitives from the point cloud. This second step has been crucial to determining the boundary conditions of the each structural element. After the first phase of automatic extraction of the perimeter, a second phase enabled the semiautomatic closing of the perimeters.

3. The closed perimeter and the internal points have allowed the NURBS interpolation for complex surfaces. This third step has been determined for the automatic creation of surfaces with subdivision UV 32x32. This specific parameter has allowed the generation of complex elements with a high level of precision and parametrization, avoiding traditional techniques such as $2 \mathrm{D}$ drawing and slicing. Thanks to exchange formats such as dwg, sat, aci etc., it was possible to transfer complex 3D objects into structural applications which that can convert NURBS model into detail meshed model for structural simulations.

4. The automatic generation of complex NURBS surface required the definition of a control system. The Automatic Verification System can automatically calculate the average distance between all the points used and the object being achieved. Figure 6 shows the AVS of the Structural Pillar of the Confederation Hall. 


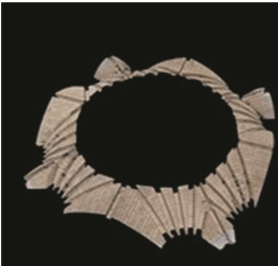

1

Dense Point - Cloud

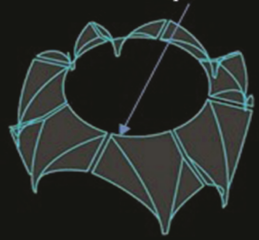

2

Extraction of Geometric primitives

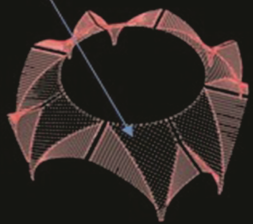

3

NURBS Interpolation (Points and Boundaries)

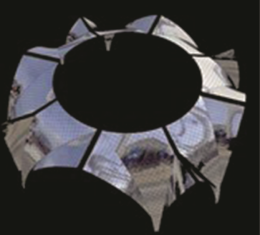

4

Automatic Generation

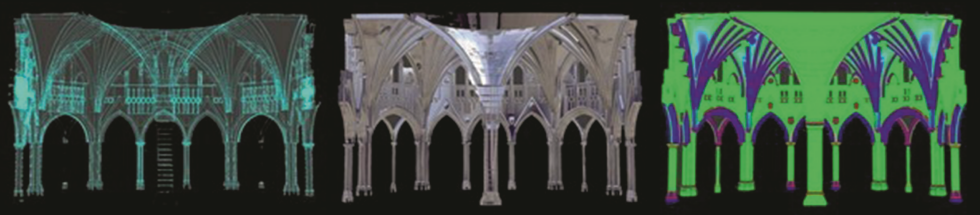

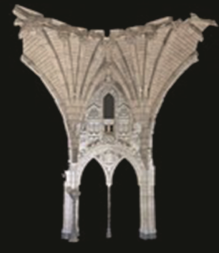

Point - Clouds

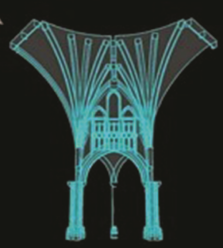

Geometric Primitives (3D Wireframe)

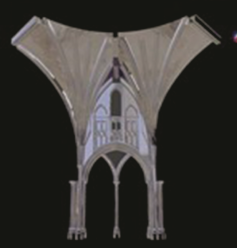

NURBS Model

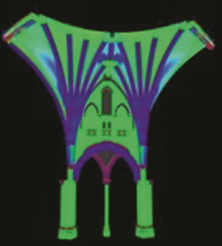

Geometric andCurvature Analysis

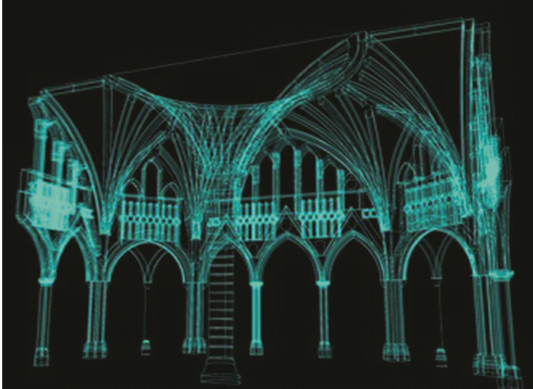

3D DIGITAL WIREFRAME OF ROTUNDA

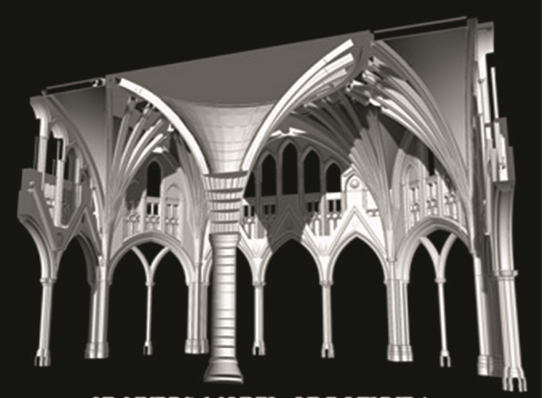

3D NURBS MODEL OF ROTUNDA
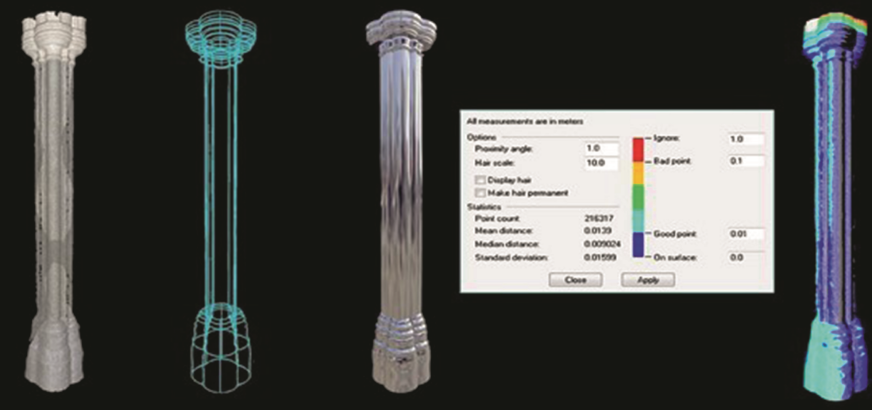

Automatic Verification System (AVS) of the Deviation Value between dense and accurate point - clouds and 3D Objects

Fig. 6. The generative process for complex structural elements and related Automatic Verification System. The Deviation value between point clouds and the 3D object is 1-2 mm. 
The median distance is $1.39 \mathrm{~mm}$. This value was obtained from each structural element located in the point cloud.

\subsection{Result and Conclusion}

The generation of complex historic 3D objects has required Advanced Modelling Tools (AMT) to manage the structural and architectural elements of the Confederation Hall of the Centre Block with a high level of detail (LOD). The case study has been an important research field to improve the integration of Non-Uniform Rational Basis-Splines (NURBS) into the parametric logic of the HBIM of the Center Block.

The study has shown that NURBS modeling represents a real need for the generative process of complex elements in parametric applications. They can reduce time and cost of the generation of the digital model for existing heritage buildings. At the same time, FEA applications are state of the art software which define advanced nonlinear and detail analysis for civil and structural engineering applications. They are specialised for refined method analysis, which requires the real geometry of each complex structural element and the related material parameters. The NURBS model of the Confederation Hall has achieved a proper definition for structural analysis and finite element analysis (FEA) with a level of accuracy around $1 / 2 \mathrm{~mm}$.

The level of accuracy (LOA) of the digital model has been verified by an automatic tool (Point/Surface Deviation) able to measure the point count (the number of points of the point clouds), the mean distance between the selected points and the selected surface,

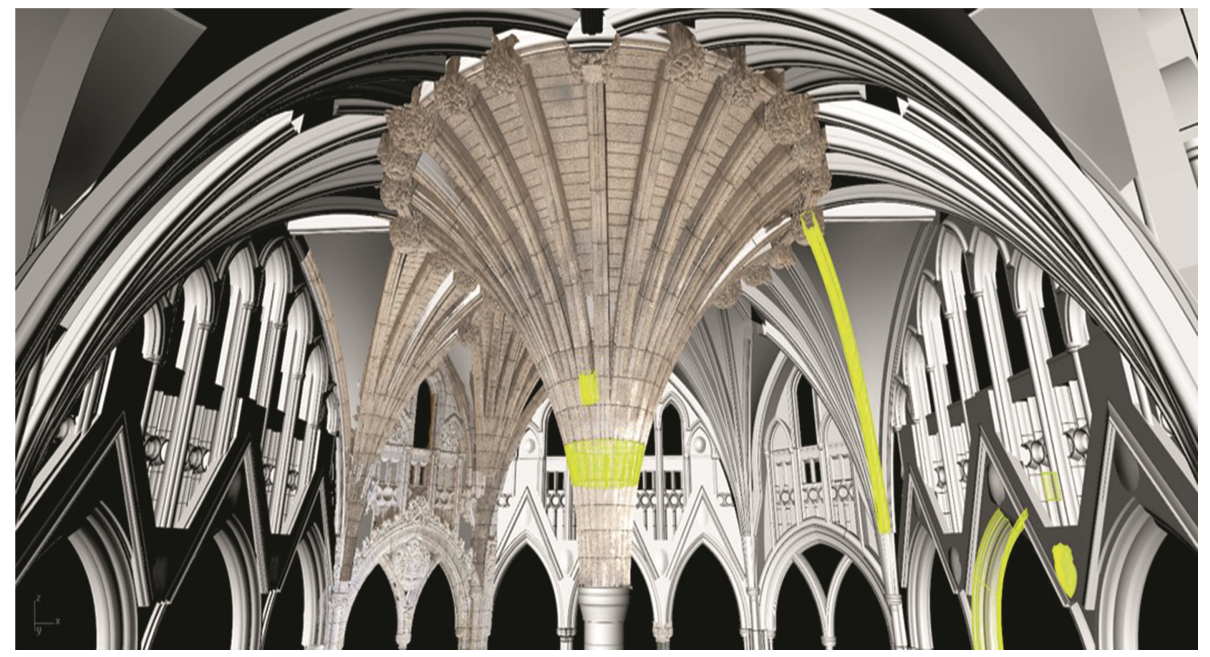

Fig. 7. The NURBS model of the Confederation Hall's complex vaulted system. The generation of each 3D object (highlighted in yellow) allows the digital management of each structural element such as arches, vaults, stones, non-vertical and complex decorations with high levels of accuracy (LOA)/information (LOI) in BIM application and in finite element analysis (FEA) software. (Color figure online) 
the median distance between the selected points and the selected surface and finally, the standard deviation between the selected points and the surface.

This analysis has been a useful Automatic Verification System (AVS) of the Deviation Value between Dense point - clouds, and 3D Objects could become a requirement to attest the quality of existing models (AS-found BIM) (Fig. 7).

Acknowledgments. This work was supported by Carleton Immersive Media Studio (CIMS), a Carleton University Research Centre, in Ottawa (Ontario). CIMS is working with Heritage Conservation Services (HCS) and the Parliamentary Precinct Directorate (PPD) of Public Services and Procurement Canada (PSPC) on the documentation and the creation of a Building Information Model (BIM) in Autodesk Revit.

The work has also been supported by the project New Paradigms/New Tools for Heritage Conservation in Canada, funded by the Social Sciences and Humanities Research Council (SSHRC) of Canada, Partnership Grants.

\section{Social Sciences and Humanities
Research Council of Canada}

Conseil de recherches en

sciences humaines du Canada

\section{Canadàt}

\section{References}

1. AIA NationallAIA California Council: Integrated Project Delivery: A Guide. Version 1, 25 May 2017. https://info.aia.org/SiteObjects/files/IPD_Guide_2007.pdf

2. Banfi, F.: Building information modelling - a novel parametric modeling approach based on $3 d$ surveys of historic architecture. In: Ioannides, M., et al. (eds.) EuroMed 2016. LNCS, vol. 10058, pp. 116-127. Springer, Cham (2016). https://doi.org/10.1007/978-3-319-48496-9_10

3. Banfi, F.: BIM orientation: grades of generation and information for different type of analysis and management process. Int. Arch. Photogrammetry Remote Sensing Spat. Inf. Sci. 42 (2017). https://doi.org/10.5194/isprs-archives-xlii-2-w5-57-2017

4. Banfi, F., Fai, S., Brumana, R.: BIM automation: advanced modeling generative process for complex structures. ISPRS Ann. Photogrammetry Remote Sensing Spat. Inf. Sci. 4 (2017)

5. Barazzetti, L., Banfi, F., Brumana, R., Gusmeroli, G., Previtali, M., Schiantarelli, G.: Cloudto-BIM-to-FEM: structural simulation with accurate historic BIM from laser scans. In: Simulation Modelling Practice and Theory, vol. 57, pp. 71-87 (2015)

6. CanBIM: AEC (CAN) BIM Protocol. CanBIM (2014). http://www.canbim.com/canbimdocuments

7. Chow, L., Fai, S.: Developing verification systems for building information models of heritage buildings with heterogeneous datasets. Int. Arch. Photogrammetry Remote Sensing Spatial Inf. Sci. 42, 125 (2017)

8. Della Torre, S.: Shaping tools for built heritage conservation: from architectural design to program and management: learning from 'Distretti culturali'. In: Community Involvement in Heritage, pp. 93-102, Garant (2015)

9. Government of Canada. Following the Rehabilitation of the Parliamentary Buildings (2017). https://www.tpsgc-pwgsc.gc.ca/citeparlementaire-parliamentaryprecinct/rehabilitation/ index-eng.html 